\title{
Strategies to Improve Accuracy and Sensitivity in Phosphorus Determinations by Inductively Coupled Plasma Quadrupole Mass Spectrometry
}

\author{
George L. Donati, * Renata S. Amais and Joaquim A. Nóbrega \\ Departamento de Química, Universidade Federal de São Carlos, CP 676, \\ 13560-970 São Carlos-SP, Brazil
}

\begin{abstract}
A interface de colisão e reação com He introduzido pelo skimmer a $100 \mathrm{~mL} \mathrm{~min}^{-1}$ é empregada para melhorar a exatidão na determinação de ${ }^{31} \mathrm{P}^{+}$por ICP-QMS. A determinação de ${ }^{31} \mathrm{P}^{16} \mathrm{O}^{+}$em plasma frio resulta em limites de detecção 55 vezes menores. Essa é uma alternativa interessante para elementos com altos potenciais de ionização como o $\mathrm{P}$.
\end{abstract}

The collision/reaction interface with He introduced through the skimmer at $100 \mathrm{~mL} \mathrm{~min}^{-1}$ is employed to improve accuracy in ${ }^{31} \mathrm{P}^{+}$determinations by ICP-QMS. The ${ }^{31} \mathrm{P}^{16} \mathrm{O}^{+}$determination in cool plasma conditions result in limits of detection 55-fold lower. This strategy may be an interesting alternative for high ionization potential elements such as $\mathrm{P}$.

Keywords: collision/reaction interface, dissociation energy, $\mathrm{H}_{2}$ reactivity, ${ }^{31} \mathrm{P}^{16} \mathrm{O}^{+}$, thermodynamics

\section{Introduction}

Inductively coupled plasma mass spectrometry (ICPMS) is one of the most powerful techniques in modern analytical chemistry. Due to its high sensitivity and multielement capabilities, ICP-MS has been used in different fields to solve important analytical problems. ${ }^{1-3}$ The reduction of costs to acquire and maintain quadrupolebased instruments (ICP-QMS) and the increasing demand for fast, sensitive and robust methods have contributed to expand ICP-MS applications in the last decades. One of the most important limitations of ICP-MS is related to its relatively low resolution. ${ }^{4}$ Spectral overlap from polyatomic ions formed by interactions among matrix, solvent, plasma and atmospheric species may compromise sensitivity and accuracy, frequently hindering ICP-QMS application to complex samples. Different approaches have been proposed to minimize the problem: from mathematical and chemical strategies to more instrumental ones (or a combination of those), all present potentialities and limitations. ${ }^{5-8}$

An interesting alternative to prevent ICP-QMS spectral interferences is to determine an analyte based on measurements of its oxide. By manipulating the plasma or the reaction cell conditions, it is possible to maximize the

*e-mail: georgedonati@yahoo.com.br oxide formation and improve sensitivity. Since a different, probably less prone to interferences mass-to-charge ratio $(\mathrm{m} / \mathrm{z})$ is monitored, the determination of oxide ions may also minimize spectral interferences. This strategy is especially useful for elements with high ionization potentials, such as $\mathrm{P}$, and some works have demonstrated its effectiveness in different applications. ${ }^{9,10}$

More recently, Kalinitchenko et al. ${ }^{11}$ proposed promoting physical-chemical interactions directly in the sampler or the skimmer cones as a simpler alternative to pressurized collision/reaction cells. ${ }^{8}$ In the collision/reaction interface technology (CRI), $\mathrm{He}$ or $\mathrm{H}_{2}$ are introduced into the system through modified sampler and skimmer cones to promote interactions capable of destroying interfering species and improving accuracy in ICP-QMS determinations. This strategy has been successfully used for different analytes ${ }^{12}$ and it has potential for applications in combination with other spectral interference-reducing methods. ${ }^{13}$

In this work, the CRI technology and the determination of oxide species are evaluated to improve sensitivity and accuracy in $\mathrm{P}$ determinations. This is a challenging element in ICP-QMS because of its relatively high ionization potential (i.e., $10.5 \mathrm{eV}$ ) ${ }^{14}$ and its severe spectral interferences. The main polyatomic ions interfering on $\mathrm{P}$ determinations at $m / z, 31$ are ${ }^{14} \mathrm{~N}^{16} \mathrm{OH}^{+}$and ${ }^{15} \mathrm{~N}^{16} \mathrm{O}^{+} .{ }^{15}$ Considering that $\mathrm{P}$ is monoisotopic and that most sample 
digestions require $\mathrm{HNO}_{3},{ }^{16}$ the difficulty of determining $\mathrm{P}$ by ICP-QMS becomes evident. Different $\mathrm{He}$ and $\mathrm{H}_{2} \mathrm{CRI}$ flow rates are evaluated for $\mathrm{P}$ determinations at $m / z 31\left({ }^{31} \mathrm{P}^{+}\right)$ and $47\left({ }^{31} \mathrm{P}^{16} \mathrm{O}^{+}\right)$. Some preliminary results are presented and physical-chemical aspects affecting the CRI efficiency in each case are discussed.

\section{Experimental}

Instrumentation

An inductively coupled plasma mass spectrometer equipped with a quadrupole mass analyzer and the CRI technology (ICP-QMS, 820-MS, Varian, Mulgrave, Australia) was used in all experiments. This instrument presents modified skimmer and sampler cones which allow the introduction of $\mathrm{H}_{2}$ or $\mathrm{He}$ directly into the plasma/mass spectrometer interface. The CRI technology is complemented by a $90^{\circ}$ angle design in which plasma source and mass spectrometer are positioned off axis to each other to reduce instrumental noise. Details on the instrument design and the CRI configuration can be found in the literature. ${ }^{11,17}$

The sample introduction system is composed of an automatic sampler (SPS3, Varian), a double pass, Scotttype spray chamber, and a concentric nebulizer. The mass-to-charge ratios $(\mathrm{m} / \mathrm{z})$ monitored were 31 and 47 for ${ }^{31} \mathrm{P}^{+}$and ${ }^{31} \mathrm{P}^{16} \mathrm{O}^{+}$, respectively. Table 1 presents the ICP-QMS operating conditions used in this work.

A closed-vessel microwave oven (Ethos 1600, Milestone, Sorisole, Italy) equipped with $45 \mathrm{~mL}$ PFA vessels was used for sample preparation.

\section{Reagents, reference solutions and samples}

Ultrapure $\mathrm{HNO}_{3}$ was produced using a sub-boiling distillation apparatus (Milestone). This reagent was used to prepare all aqueous solutions and to digest the sample aliquots. Hydrogen peroxide $30 \%(\mathrm{~m} / \mathrm{m})$ was also used in the microwave-assisted acid digestion of the sample aliquots. Distilled-deionized water (18.2 $\mathrm{M} \Omega \mathrm{cm}$, Milli-Q, Millipore, Bedford, MA, USA) was used as solvent in all experiments. Standard reference solutions of $P$ were prepared by appropriated dilution of a $1000 \mathrm{mg} \mathrm{L}^{-1}$ stock solution (Tec-Lab, Hexis, São Paulo, SP, Brazil). Freshly collected tap water was spiked with $1.0 \mathrm{mg} \mathrm{L}^{-1} \mathrm{P}$ and used as test solution to optimize the CRI conditions. A standard reference material (SRM 1548a, "Typical Diet") from the National Institute of Standards and Technology (NIST, Gaithersburg, MD, USA) was used to check the method accuracy.
All polypropylene material was kept in $10 \%$ (v/v) $\mathrm{HNO}_{3}$ overnight and rinsed with distilled-deionized water before use to prevent contaminations. Liquid Ar and the CRI gases ( $\mathrm{He}$ and $\mathrm{H}_{2}$ ) used in this work were $99.999 \%$ pure (White Martins, Sertãozinho, SP, Brazil).

Table 1. ICP-QMS operating conditions

\begin{tabular}{lc}
\hline Instrumental parameter & Operating condition \\
\hline Plasma gas flow rate / $\left(\mathrm{L} \mathrm{min}^{-1}\right)$ & 18.0 \\
Auxiliary gas flow rate / $\left(\mathrm{L} \mathrm{min}^{-1}\right)$ & 1.8 \\
Nebulizer gas flow rate / $\left(\mathrm{L} \mathrm{min}^{-1}\right)$ & $0.94^{\mathrm{a}}$ \\
Sheath gas flow rate / $\left(\mathrm{L} \mathrm{min}^{-1}\right)$ & 0.17 \\
Peristaltic pump rate / rpm & 6 \\
Sampling depth / mm & 5.5 \\
RF power / kW & $1.4^{\mathrm{a}}$ \\
Points per peak & 3 \\
Scans per replicate & 3 \\
Replicate per sample & 5 \\
Dwell time / ms & $1^{\mathrm{a}}$ \\
First extraction lens / V & -1 \\
Second extraction lens / V & -173 \\
Third extraction lens / V & -247 \\
Corner lens / V & -318 \\
Mirror lens right / V & 43 \\
Mirror lens left / V & 39 \\
Mirror lens bottom / V & 29 \\
Entrance lens / V & 0 \\
Fringe bias / V & -2.5 \\
Entrance plate / V & -27 \\
\hline
\end{tabular}

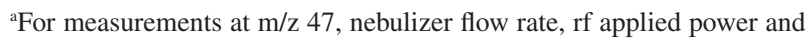
dwell time were set to $1.0 \mathrm{~L} \mathrm{~min}^{-1}, 0.9 \mathrm{~kW}$ and $40 \mathrm{~ms}$, respectively.

\section{Sample preparation}

Freshly collected tap water aliquots of $5 \mathrm{~mL}$ were spiked with $\mathrm{P}$ and diluted to $10 \mathrm{~mL}$ with distilled-deionized water to a final concentration of $1.0 \mathrm{mg} \mathrm{L}^{-1}$.

Typical Diet (NIST 1548a) aliquots of approximately $250 \mathrm{mg}$ were accurately weighted directly in microwave PFA vessels and submitted to a pre-digestion period of 60 min with $2.5 \mathrm{~mL}$ of concentrated $\mathrm{HNO}_{3}\left(14 \mathrm{~mol} \mathrm{~L}^{-1}\right)$ without any external heating. Then, $2.5 \mathrm{~mL}$ of distilleddeionized water were added to the mixture and an additional pre-digestion period of $30 \mathrm{~min}$ at room temperature was observed. Finally, a volume of $3.0 \mathrm{~mL}$ of $\mathrm{H}_{2} \mathrm{O}_{2} 30 \%(\mathrm{~m} / \mathrm{m})$ was added and the mixture was digested in a closed-vessel cavity microwave oven (Milestone) using the heating program presented in Table 2. The resulting solutions were then allowed to cool down, transferred to $15 \mathrm{~mL}$ 
polypropylene flasks, and diluted to a final volume of $10 \mathrm{~mL}$ with distilled-deionized water. Additional dilution was performed just before analysis to adjust the $\mathrm{P}$ concentration to the analytical calibration curve linear dynamic range.

Table 2. Heating program employed in the microwave-assisted sample digestion of Typical Diet

\begin{tabular}{lccc}
\hline Step & Applied power $/ \mathrm{W}$ & time $/ \mathrm{min}$ & Temperature $/{ }^{\circ} \mathrm{C}$ \\
\hline 1 & 250 & 2 & 80 \\
2 & 0 & 3 & 80 \\
3 & 550 & 4 & 120 \\
4 & 650 & 5 & 180 \\
5 & 750 & 5 & 200 \\
\hline
\end{tabular}

\section{Optimization of the CRI conditions}

Different CRI flow rates were evaluated for $\mathrm{He}$ or $\mathrm{H}_{2}$ introduced through the skimmer or the sampler cones. For ${ }^{31} \mathrm{P}^{+}$determinations, He flow rates of $40,60,80$ and $100 \mathrm{~mL} \mathrm{~min}^{-1}$ introduced through the skimmer, and of 500, 1000 and $1500 \mathrm{~mL} \mathrm{~min}^{-1}$ introduced through the sampler were evaluated. Hydrogen gas introduced through the skimmer at 20, 40 and $60 \mathrm{~mL} \mathrm{~min}^{-1}$, and through the sampler at 200, 1000 and $1500 \mathrm{~mL} \mathrm{~min}^{-1}$ was also evaluated. For ${ }^{31} \mathrm{P}^{16} \mathrm{O}^{+}$, determinations without the CRI and with $\mathrm{H}_{2}$ flowing at $40 \mathrm{~mL} \mathrm{~min}^{-1}$ through the skimmer were compared.

\section{Results and Discussion}

\section{Determinations at $\mathrm{m} / \mathrm{z} 31$}

The CRI efficiency at reducing spectral interferences in ${ }^{31} \mathrm{P}^{+}$determinations was evaluated by comparing recoveries obtained for a tap water sample spiked with $1.0 \mathrm{mg} \mathrm{L}^{-1} \mathrm{P}$ in different $\mathrm{He}$ or $\mathrm{H}_{2}$ flow rates. As observed in previous works, ${ }^{11-13}$ the sampler cone interface was not efficient and recoveries from 22 to $80 \%$ were obtained. For determinations using the skimmer cone interface, recoveries varied from 60 to $94 \%$. Table 3 presents the results for $\mathrm{He}$ and $\mathrm{H}_{2}$ in different flow rates.

Based on these results, conditions presenting recoveries higher than $85 \%$, i.e., $\mathrm{He}$ at 80 and $100 \mathrm{~mL} \mathrm{~min}^{-1}$, and $\mathrm{H}_{2}$ at $40 \mathrm{~mL} \mathrm{~min}{ }^{-1}$, were used to determine $\mathrm{P}$ in a standard reference material (Typical Diet, NIST 1548a). The goal in this case was to check the method efficiency for a more complex matrix. No statistically significant difference at a 95\% confidence level was observed between the certified value ( $\left.3486 \pm 245 \mathrm{mg} \mathrm{kg}^{-1}\right)$ and the ones determined using $\mathrm{He}$ at 80 or $100 \mathrm{~mL} \mathrm{~min}^{-1}$ in the skimmer cone $(3960 \pm 270$ and $3350 \pm 250 \mathrm{mg} \mathrm{kg}^{-1}$, respectively). On the other hand, a lower accuracy was observed for determinations using $\mathrm{H}_{2}$ at $40 \mathrm{~mL} \mathrm{~min}^{-1}$ in the skimmer, i.e., $3010 \pm 60 \mathrm{mg} \mathrm{kg}^{-1}$.

Kinetic and thermodynamic aspects must be considered while applying the CRI to minimize ICP-QMS spectral interferences. Helium is essentially used as a collision gas that may destroy interfering ions by collision induced dissociation (CID). However, it may only be efficient if the collision energy is higher than the interfering ion dissociation energy (Do). ${ }^{18}$ As previously demonstrated by Kovacevic et al. ${ }^{15}$ the main interfering ions affecting ${ }^{31} \mathrm{P}^{+}$determinations in $\mathrm{HNO}_{3}$ medium are ${ }^{14} \mathrm{~N}^{16} \mathrm{OH}^{+}(65 \%$ abundance) and ${ }^{15} \mathrm{~N}^{16} \mathrm{O}^{+}$(32\% abundance). By calculating the collision energy in the center of mass between $\mathrm{He}$ and these ions $\left(\mathrm{E}_{\mathrm{cm}} \mathrm{He} / 31=0.46 \mathrm{eV}\right),{ }^{19}$ and comparing it with the dissociation energies (Do $=0.395$ and $10.85 \mathrm{eV}$ for ${ }^{14} \mathrm{~N}^{16} \mathrm{OH}^{+}$and ${ }^{15} \mathrm{~N}^{16} \mathrm{O}^{+}$, respectively), ${ }^{14,19}$ one can assume that the CRI on collision mode could only be effective at minimizing spectral overlap from ${ }^{14} \mathrm{~N}^{16} \mathrm{OH}^{+}$. Considering

Table 3. Effects of the CRI collision $(\mathrm{He})$ and reaction $\left(\mathrm{H}_{2}\right)$ modes on ICP-QMS accuracy for ${ }^{31} \mathrm{P}^{+}$determinations

\begin{tabular}{|c|c|c|c|c|}
\hline \multirow{2}{*}{ Gas } & \multicolumn{2}{|c|}{ Sampler } & \multicolumn{2}{|c|}{ Skimmer } \\
\hline & Gas flow rate $/\left(\mathrm{mL} \mathrm{min}^{-1}\right)$ & Found $/\left(\mathrm{mg} \mathrm{L}^{-1}\right)^{\mathrm{a}}$ & Gas flow rate / $\left(\mathrm{mL} \min ^{-1}\right)$ & Found / $\left(\mathrm{mg} \mathrm{L}^{-1}\right)^{\mathrm{a}}$ \\
\hline \multirow[t]{4}{*}{$\mathrm{H}_{2}$} & 0 & $0.74 \pm 0.07$ & 0 & $0.74 \pm 0.07$ \\
\hline & 200 & $0.79 \pm 0.04$ & 20 & $0.78 \pm 0.07$ \\
\hline & 1000 & $0.66 \pm 0.20$ & 40 & $0.94 \pm 0.07$ \\
\hline & 1500 & $0.22 \pm 0.02$ & 60 & $0.70 \pm 0.04$ \\
\hline \multirow[t]{5}{*}{$\mathrm{He}$} & 0 & $0.74 \pm 0.07$ & 0 & $0.74 \pm 0.07$ \\
\hline & 500 & $0.80 \pm 0.08$ & 40 & $0.68 \pm 0.05$ \\
\hline & 1000 & $0.79 \pm 0.04$ & 60 & $0.82 \pm 0.04$ \\
\hline & 1500 & $0.79 \pm 0.05$ & 80 & $0.87 \pm 0.03$ \\
\hline & & & 100 & $0.90 \pm 0.10$ \\
\hline
\end{tabular}

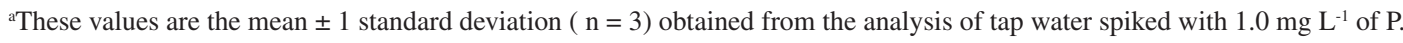


the ICP-MS conditions and ${ }^{15} \mathrm{~N}$ low natural abundance (i.e., $0.37 \%$ ), it may be supposed that ${ }^{14} \mathrm{~N}^{16} \mathrm{OH}^{+}$is the species responsible for most significant spectral interferences, which could explain the adequate accuracies obtained for determinations using $\mathrm{He}$ in the skimmer cone.

It is important to note that the accuracy obtained in this work may also be related to more efficient sample matrix decompositions. It has been demonstrated that high residual carbon contents (RCC) can compromise accuracy in ${ }^{31} \mathrm{P}^{+}$ determinations, probably due to a higher concentration of carbon-based interfering ions such as ${ }^{12} \mathrm{C}^{18} \mathrm{OH}^{+} .{ }^{15}$ In a previous work using the same standard reference material and the CRI on collision mode, poor accuracies were observed probably because no pre-digestion step was employed and digested sample solutions with higher RCCs were probably obtained. ${ }^{7}$ Considering ${ }^{12} \mathrm{C}^{18} \mathrm{OH}^{+}$as the main carbon-based interfering ion in high RCC solutions, ${ }^{15}$ and comparing $\mathrm{E}_{\mathrm{cm}} \mathrm{He} / 31$ and Do values (0.46 and $6.14 \mathrm{eV}$, respectively), ${ }^{14,19}$ the reason for such poor accuracies ${ }^{7}$ becomes evident.

On the other hand, no kinetic data are available for reactions between $\mathrm{H}_{2}$ and either of these interfering ions. ${ }^{20}$ In addition, reactions represented by equations $1-3^{14,21}$ indicate that they are thermodynamically non-favorable since they are all endothermic. Therefore, as it would be expected and it is confirmed by the Typical Diet results, the CRI on reaction mode is not effective at improving accuracy in ${ }^{31} \mathrm{P}^{+}$determinations.

$$
\begin{array}{ll}
\mathrm{NO}^{+}+\mathrm{H}_{2} \rightarrow \mathrm{NOH}^{+}+\mathrm{H} & \Delta \mathrm{H}=397.9 \mathrm{~kJ} \mathrm{~mol}^{-1} \\
\mathrm{NOH}^{+}+\mathrm{H}_{2} \rightarrow \mathrm{NO}+\mathrm{H}_{3}^{+} & \Delta \mathrm{H}=123.0 \mathrm{~kJ} \mathrm{~mol}^{-1} \\
\mathrm{COH}^{+}+\mathrm{H}_{2} \rightarrow \mathrm{CO}+\mathrm{H}_{3}^{+} & \Delta \mathrm{H}=169.2 \mathrm{~kJ} \mathrm{~mol}^{-1}
\end{array}
$$

\section{Determinations at $m / z 47$}

As previously demonstrated in different works, ${ }^{9,10}$ the determination of $\mathrm{P}$ as $\mathrm{PO}^{+}$at $\mathrm{m} / z 47$ may be an interesting alternative to improve sensitivity and minimize interferences in ICP-QMS analyses. The $\mathrm{PO}^{+}$ion is readily formed in the plasma as demonstrated in equation 4 $\left(\mathrm{k}=8.70 \times 10^{-10} \mathrm{~cm}^{3} \mathrm{~s}^{-1}\right) .{ }^{22}$ Since this is an exothermic reaction, its formation may be maximized by reducing the plasma temperature. This effect can be obtained by reducing the radio-frequency (rf) applied power and increasing the nebulizer gas flow rate (Table 1). It is interesting to note that a higher nebulizer gas flow rate can have a two-fold positive effect on maximizing the $\mathrm{PO}^{+}$formation since it may also increase the number of non-ionized water molecules available.

$\mathrm{P}^{+}+\mathrm{H}_{2} \mathrm{O} \rightarrow \mathrm{PO}^{+}+\mathrm{H}_{2} \quad \Delta \mathrm{H}=-300.5 \mathrm{~kJ} \mathrm{~mol}^{-1}$
The efficiency of a method combining the CRI strategy and $\mathrm{PO}^{+}$determination in cooler plasma conditions was evaluated by analyzing recoveries in a tap water sample spiked with $1.0 \mathrm{mg} \mathrm{L}^{-1} \mathrm{P}$. Two aspects need to be considered while using the CRI for oxide ion determinations: the analyte should present both high dissociation energy and limited reactivity with $\mathrm{H}_{2}$ so it is not destroyed in the interface. Table 4 presents the dissociation energies for $\mathrm{PO}^{+}$and its main interfering ions (i.e., ${ }^{14} \mathrm{~N}^{16} \mathrm{O}_{2} \mathrm{H}^{+},{ }^{15} \mathrm{~N}^{16} \mathrm{O}_{2}^{+}$, ${ }^{12} \mathrm{C}^{35} \mathrm{Cl}^{+},{ }^{13} \mathrm{C}^{18} \mathrm{O}^{16} \mathrm{O}^{+}$, and $\left.{ }^{12} \mathrm{C}^{18} \mathrm{O}^{16} \mathrm{OH}^{+}\right),{ }^{15}$ as calculated using thermodynamic data from the literature. ${ }^{14}$ By comparing these values with the collision energy in the center of mass between $\mathrm{He}$ and those species $\left(\mathrm{E}_{\mathrm{cm}} \mathrm{He} / 47=0.31 \mathrm{eV}\right),{ }^{19}$ it can be assumed that neither the analyte will be dissociated nor the CRI on collision mode will be effective at minimizing the main spectral interferences at $\mathrm{m} / \mathrm{z} 47$. The same reasoning may be applied for determinations using the CRI on reaction mode and by analyzing the energies involved in reactions represented by equations 5-10. ${ }^{14,21,23}$ Based on these data and considering the sampler interface low efficiency, ${ }^{11-13}$ only two CRI conditions were evaluated for ${ }^{31} \mathrm{P}^{16} \mathrm{O}^{+}$determinations: $\mathrm{H}_{2}$ at 0 or $40 \mathrm{~mL} \mathrm{~min}^{-1}$ introduced through the skimmer. The results for spiked tap water and Typical Diet are presented in Table 5. As expected, no accuracy improvements were observed by employing the CRI in each case.

$$
\begin{array}{ll}
\mathrm{PO}^{+}+\mathrm{H}_{2} \rightarrow \mathrm{POH}^{+}+\mathrm{H} & \Delta \mathrm{H}=256.5 \mathrm{~kJ} \mathrm{~mol}^{-1} \\
\mathrm{NO}_{2} \mathrm{H}^{+}+\mathrm{H}_{2} \rightarrow \mathrm{NO}_{2}+\mathrm{H}_{3}^{+} & \Delta \mathrm{H}=126.3 \mathrm{~kJ} \mathrm{~mol}^{-1} \\
\mathrm{NO}_{2}^{+}+\mathrm{H}_{2} \rightarrow \mathrm{NO}_{2} \mathrm{H}^{+}+\mathrm{H} & \Delta \mathrm{H}=272.2 \mathrm{~kJ} \mathrm{~mol}^{-1} \\
\mathrm{CCl}^{+}+\mathrm{H}_{2} \rightarrow \mathrm{HCl}+\mathrm{HC}^{+} & \Delta \mathrm{H}=167.6 \mathrm{~kJ} \mathrm{~mol}^{-1} \\
\mathrm{CO}_{2}^{+}+\mathrm{H}_{2} \rightarrow \mathrm{CO}_{2} \mathrm{H}^{+}+\mathrm{H} & \Delta \mathrm{H}=-148.8 \mathrm{~kJ} \mathrm{~mol}^{-1} \\
\mathrm{CO}_{2} \mathrm{H}^{+}+\mathrm{H}_{2} \rightarrow \mathrm{CO}_{2}+\mathrm{H}_{3}^{+} & \Delta \mathrm{H}=144.21 \mathrm{~kJ} \mathrm{~mol}^{-1}
\end{array}
$$

Table 4. Dissociation energies (Do) for $\mathrm{PO}^{+}$and its main interfering ions in ICP-QMS determinations at $\mathrm{m} / \mathrm{z} 47$

\begin{tabular}{lc}
\hline Ion & Do / eV \\
\hline $\mathrm{PO}^{+}$ & 8.20 \\
$\mathrm{NO}_{2} \mathrm{H}^{+}$ & 1.70 \\
$\mathrm{NO}_{2}^{+}$ & 1.91 \\
$\mathrm{CCl}^{+}$ & 6.84 \\
$\mathrm{CO}_{2}^{+}$ & 5.36 \\
$\mathrm{CO}_{2} \mathrm{H}^{+}$ & 5.88 \\
\hline
\end{tabular}

Limits of detection and quantification

The instrumental limits of detection (LOD) and quantification (LOQ) for different CRI conditions were calculated and compared with determinations without the CRI. The results are presented in Table 6. As it can be seen, 
Table 5. Effects of using the CRI on reaction mode for ${ }^{31} \mathrm{P}^{16} \mathrm{O}^{+}$determinations

\begin{tabular}{|c|c|c|c|}
\hline Sample & Skimmer $\mathrm{H}_{2}$ flow rate $/\left(\mathrm{mL} \mathrm{min}^{-1}\right)$ & Reference & Found $^{\mathrm{a}}$ \\
\hline \multirow[t]{2}{*}{ Spiked tap water $/\left(\mathrm{mg} \mathrm{L}^{-1}\right)$} & 0 & 1.0 & $1.19 \pm 0.02$ \\
\hline & 40 & & $1.16 \pm 0.04$ \\
\hline \multirow[t]{2}{*}{ Typical Diet $/\left(\mathrm{mg} \mathrm{kg}^{-1}\right)$} & 0 & $3486 \pm 245$ & $4140 \pm 150$ \\
\hline & 40 & & $4240 \pm 150$ \\
\hline
\end{tabular}

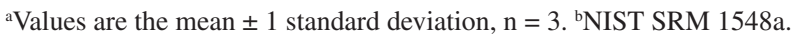

Table 6. Limits of detection (LOD) and quantification (LOQ) for ${ }^{31} \mathrm{P}^{+}$and ${ }^{31} \mathrm{P}^{16} \mathrm{O}^{+}$determined with or without the CRI

\begin{tabular}{|c|c|c|c|c|c|}
\hline Analyte & CRI gas & Skimmer flow rate $/\left(\mathrm{mL} \min ^{-1}\right)$ & $\mathrm{BEC}^{\mathrm{a}} /\left(\mu \mathrm{g} \mathrm{L}^{-1}\right)$ & $\mathrm{LOD} /\left(\mu \mathrm{g} \mathrm{L}^{-1}\right)$ & $\mathrm{LOQ} /\left(\mu \mathrm{g} \mathrm{L}^{-1}\right)$ \\
\hline \multirow[t]{5}{*}{${ }^{31} \mathrm{P}^{+}$} & $\mathrm{He}$ & 0 & 62 & 30 & 100 \\
\hline & & 80 & 650 & 560 & 1900 \\
\hline & & 100 & 190 & 110 & 370 \\
\hline & $\mathrm{H}_{2}$ & 0 & 62 & 30 & 100 \\
\hline & & 40 & 76 & 70 & 230 \\
\hline \multirow[t]{2}{*}{${ }^{31} \mathrm{P}^{16} \mathrm{O}^{+}$} & $\mathrm{H}_{2}$ & 0 & 4.7 & 2.0 & 7.0 \\
\hline & & 40 & 2.3 & 5.0 & 17 \\
\hline
\end{tabular}

significant improvements were obtained for determinations at $m / z 47$, probably due to lower background signals in a less energetic plasma. The LODs were calculated as 3 times the background equivalent concentration (BEC) multiplied by the relative standard deviation of twenty consecutive blank determinations (RSD, $n=20$ ). The BEC was calculated by dividing the analyte concentration in one of the calibration curve points by its respective signal-to-background ratio (SBR). SBR is the net analytical signal divided by the blank signal. ${ }^{24}$ The LOQ as calculated as 10 times BEC multiplied by RSD.

\section{Conclusions}

The collision/reaction interface can be effective at improving accuracy in ICP-QMS determinations. However, kinetic and thermodynamic aspects need to be considered while developing methods based on this technology. The CRI on collision mode may be effective for determinations involving interfering species with both low mass and low dissociation energies. Considering accuracy and limits of detection in ${ }^{31} \mathrm{P}^{+}$determinations, the introduction of $\mathrm{He}$ at $100 \mathrm{~mL} \mathrm{~min}{ }^{-1}$ through the skimmer is the most recommended condition.

Monitoring $\mathrm{PO}^{+}$in cool plasma conditions is an interesting alternative to improve ICP-QMS sensitivity. Comparing this strategy with the optimized CRI method for ${ }^{31} \mathrm{P}^{+}$, a 55-fold improvement in the LOD was obtained. On the other hand, a larger number of interfering ions with relatively high ionization energies and low reactivity with $\mathrm{H}_{2}$ can compromise both the CRI efficiency and the method accuracy for determinations at the $m / z 47$.

\section{Acknowledgments}

The authors would like to thank the Fundação de Amparo à Pesquisa do Estado de São Paulo (FAPESP) for the grants and fellowships provided (2006/59083-9, 2010/50238-5, and 2010/17387-7). The support from the Instituto Nacional de Ciências e Tecnologias Analíticas Avançadas and Conselho Nacional de Desenvolvimento Científico e Tecnológico (INCTAA and CNPq) is also greatly appreciated.

\section{References}

1. Avula, B.; Wang, Y.; Duzgoren-Aydin, N. S.; Khan, I. K.; Food Chem. 2011, 127, 54.

2. Sussulini, A.; Banzato, C. E. M.; Arruda, M. A. Z.; Int. J. Mass Spectrom. 2011, 307, 182.

3. Oliveira, E. P.; Yang, L.; Sturgeon, R. E.; Santelli, R. E.; Bezerra, M. A.; Willie, S. N.; Capilla, R.; J. Anal. At. Spectrom. 2011, 26,578 .

4. Becker, J. S.; Inorganic Mass Spectrometry: Principles and Applications; Wiley: Chichester, 2008.

5. Thomas, R.; Spectroscopy 2002, 17, 24.

6. Tanner, S. D.; J. Anal. At. Spectrom. 1995, 10, 905.

7. Donati, G. L.; Amais, R. S.; Nóbrega, J. A.; J. Anal. At. Spectrom. 2011, 26, 1827. 
8. D’Ilio, S.; Violante, N.; Majorani, C.; Petrucci, F.; Anal. Chim. Acta 2011, 698, 6.

9. Yang, C.; Jiang, S.; Spectrochim. Acta, Part B 2004, 59, 1389.

10. Ciavardelli, D.; Sacchetta, P.; Federici, G.; Di Ilio, C.; Urbani, A.; Talanta 2010, 80, 1513.

11. Kalinitchenko, I.; Wang, X.; Sturman, B.; Spectroscopy 2008, 23, 38 .

12. Pereira, C. D.; Garcia, E. E.; Silva, F. V.; Nogueira, A. R. A.; Nóbrega, J. A.; J. Anal. At. Spectrom. 2010, 25, 1763.

13. Fialho, L. L.; Pereira, C. D.; Nóbrega, J. A.; Spectrochim. Acta, Part B 2011, 66, 389.

14. National Institute of Standards and Technology, Chemistry WebBook, NIST Standard Reference Database. http://webbook. nist.gov/chemistry/form-ser.html accessed in October 2011.

15. Kovacevic, M.; Goessler, W.; Mikac, N.; Veber, M.; Anal. Bioanal. Chem. 2005, 383, 145.

16. Nóbrega, J. A.; Donati, G. L. In Encyclopedia of Analytical Chemistry; Meyers, R. A.; Bings, N. H., eds.; Wiley: Chichester, 2011.
17. Elliot, S.; Knowles, M.; Kalinitchenko, I.; Spectroscopy 2004, $19,30$.

18. Bandura, D. R.; Baranov, V. I.; Tanner, S. D.; Fresenius J. Anal. Chem. 2001, 370, 454.

19. Houk, R. S.; Praphairaksit, N.; Spectrochim. Acta, Part B 2001, $56,1069$.

20. Anicich, V. G.; Astrophys. J. Suppl. S. 1993, 84, 215.

21. Oka, T.; Proc. Natl. Acad. Sci. U.S.A. 2006, 103, 12235.

22. Thorne, L. R.; Anicich, V. G.; Huntress, Jr., W. T.; Chem. Phys. Lett.1983, 98, 162.

23. Green, S.; Schor, H.; Siegbahn, P.; Thaddeus, P.; Chem. Phys. 1976, 17,479 .

24. Thomsen, V.; Roberts, G.; Burguess, K.; Spectroscopy 2000 , 15,33 .

Submitted: November 22, 2011

Published online: February 2, 2012

FAPESP has sponsored the publication of this article. 